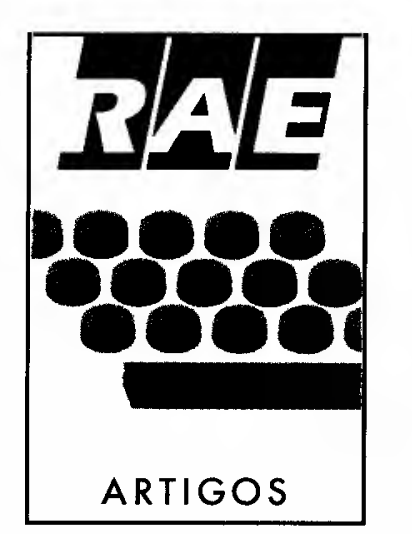

\title{
PÓLOS TECNOLÓGICOS E DE MODERNIZAÇÃO: NOTAS SOBRE A EXPERIÊNCIA BRASILEIRA
}

A articulação entre empresas, centros de $P \& D$, universidades e governos é um dos mais importantes instrumentos de desenvolvimento regional e local na atualidade.

The articulation between enterprises, $R \mathcal{E} D$ centers, universities and governments is one of the most important local and regional development instruments in the present.

\section{PALAVRAS-CHAVE:}

Inovação tecnológica, localizaçã̃o Industrlal, empresa de base tecnológica, parque cientifico-tecnológico, novas estratégias tecnológicas de risco, administração empreendedora.

\section{KEY WORDS:}

Technological innovation, plant location, technology-based flrm, science park, hlgh-tech newai ventures, entrepreneurl management.

"Professor do Departamento de Administração de Produção, Logística e Operaçōes Industriais (POI) e Centro de Política e Gestão Tecnológica (CPGT) da EAESP/FGV.

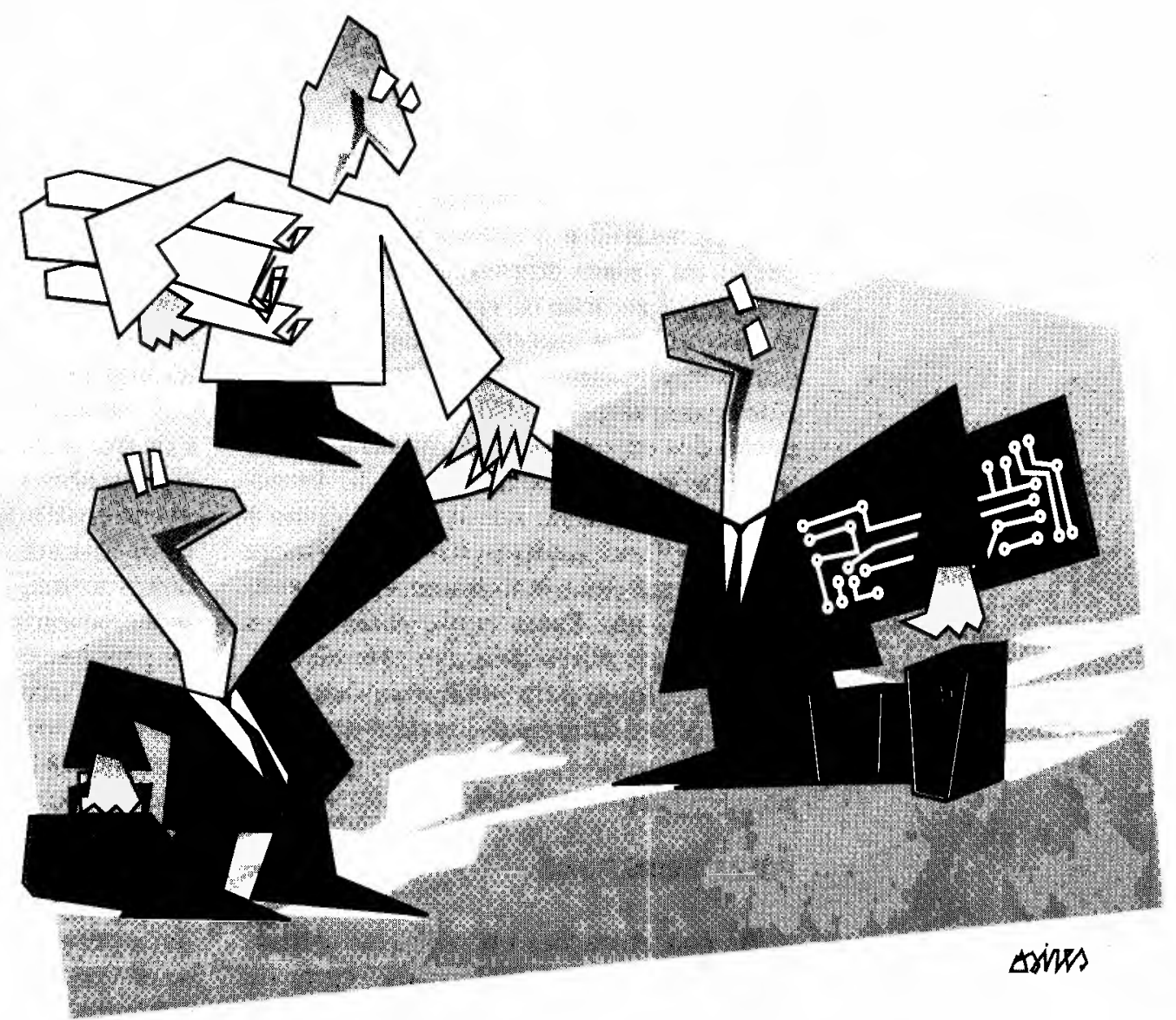


Os pólos e os parques tecnológicos e de modernização têm se constituído em instrumentos básicos de dinamização das economias desenvolvidas, seguindo o sucesso de experiências como a do Vale do Silício na Califórnia, da Rota 128 em Massachusetts e das cidades tecnológicas da França e do Japão. Esse tipo de empreendimento, que envolve governos, instituições de ensino e pesquisa -IEPs, pesquisadores-empresários e capitais de risco, está em consonância com as características das novas tecnologias intensivas em pesquisas de ponta. $O$ entendimento sobre esses pólos e parques tecnológicos e de modernização tem sido dificultado não

\section{$\bullet \bullet \bullet \bullet$ \\ Comum a todos os pólos tecnológicos e de modernização é a presença de diversos agentes representados pelo tripé governo-instituição de ensino e pesquisa-setor produtivo, em intensa interação. $\bullet \bullet \bullet \bullet$}

só pela variedade de situações reais, mas principalmente pela retórica governamental, empresarial e acadêmica sobre a importância desses empreendimentos para a região, a geração de empregos etc. Esse assunto envolve questões polêmicas como, por exemplo, a interação instituição de ensino e pesquisa-setor produtivo; a participação das empresas de pequeno e médio porte no processo de incorporação de tecnologias de ponta; novas abordagens à teoria da localização industrial; alianças estratégicas; desenvolvimento de empreendedores etc. Fatos como esses fazem com que seja necessário, em primeiro lugar, um esforço para melhor caracterizar esses pólos e diferenciá-los de outros empreendimentos assemelhados, como os pólos industriais tradicionais.

\section{PÓLOS INDUSTRIAIS}

As concentrações ou pólos industriais tradicionais decorrem, via de regra, da existência de fatores localizacionais clás- sicos como proximidade dos mercados consumidores, acesso aos fornecedores, mercado de trabalho abundante, infra-estrutura física adequada, serviços industriais de utilidade pública etc. A estes acrescentam-se os incentivos governamentais, tanto os de natureza tributária como isenções e reduções de impostos e taxas, quanto os de natureza infra-estrutural, como, por exemplo, a criação de distritos industriais, a doação de terrenos, as obras de terraplanagem, os serviços de transporte coletivo, as facilidades para instalações elétricas, as redes de água e esgoto etc. A criação desses incentivos objetiva complementar os fatores localizacionais existentes na região (macrolocalização) ou no local específico (microlocalização), bem como suprir a falta deles. Grosso modo, as ações governamentais em torno desses pólos tradicionais não levam em conta o tipo de tecnologia utilizada pelas firmas, nem a forma como essas tecnologias são obtidas. A industrialização em São Paulo e no ABC paulista são exemplos de concentrações espontâneas formadas basicamente em decorrência da preexistência daqueles fatores localizacionais clássicos nessas regiões. A Zona Franca de Manaus é um exemplo de pólo onde os fatores localizacionais básicos foram e continuam sendo os incentivos governamentais criados para suprir a falta de atratividade natural na região para as empresas industriais.

Comum a todos os pólos tecnológicos e de modernização é a presença de diversos agentes representados pelo tripé governo-instituição de ensino e pesquisasetor produtivo, em intensa interação. E, dessa forma, as iniciativas desse gênero se inscrevem como solução ampliada para os problemas, proverbialmente conhecidos, que ocorrem nas interfaces entre os agentes produtores de conhecimentos científicos e tecnológicos e os agentes usuários desses conhecimentos. Dito de outra forma, tratam-se de empreendimentos voltados para a realização de inovações tecnológicas com elevado grau de novidade para o mercado. E como tais, tratamse de empreendimentos integrativos, que contemplam esforços combinados a jusan- 
te e a montante da inovação propriamente dita, ainda que de modo informal e pouco articulado, como são os casos dos empreendimentos de caráter espontâneo. As inovações, objetos dessas iniciativas, situam-se nas áreas das novas tecnologias (mecânica de precisão, química fina, novos materiais, informática etc.) através da criação de empresas de base tecnológica e da incorporação de inovação dessa natureza em setores tradicionais ou maduros. No primeiro caso, estão os pólos científico-tecnológicos; no segundo, os de modernização.

\section{EMPRESAS DE BASE TECNOLÓGICAS}

Nos pólos de modernização, as inovações tecnológicas e a articulação com as IEPs objetivam prover a atualização tecnológica e organizacional de empresas já existentes na região, geralmente pequenas e médias empresas que não teriam condições de realizar tais intentos isoladamente. Nos pólos tecnológicos ocorre a proliferação de empresas de alta tecnologia ou de base tecnológica, criando, dessa forma, novos segmentos industriais. Dorfman utiliza a expressão high tech concentration para descrever a aglomeração de empreendimentos voltados para o projeto, desenvolvimento ou produção de um novo produto ou processo através da aplicação sistemática de conhecimentos científicos e tecnológicos e da utilização intensiva de tecnologias avançadas ${ }^{1}$. Parece ser daí que o BNDESPAR - BNDES Participações S/A - se apoiou para elaborar a sua definição de empresas de base tecnológica. Pois, de acordo com seu Regulamento 49/91, a empresa de base tecnológica é aquela que fundamenta sua atividade produtiva no desenvolvimento de novos produtos ou processos, baseados na aplicação sistemática de conhecimentos científicos e tecnológicos e na utilização de técnicas consideradas avançadas ou pioneiras (Artigo $2^{\circ}, b$ ).

Para Bollinger et al., que utilizam a expressão "empresas baseadas em novas tecnologias", essas empresas teriam as seguintes características: são de pequeno porte, onde claramente se identifica o pequeno núcleo de seus fundadores; são totalmente independentes, isto é, não fazem parte ou não são subsidiárias de uma grande empresa; e a motivação básica para a sua criação foi a de explorar uma idéia tecnologicamente inovadora ${ }^{2}$. Dessas características, apenas a última está presente em todas as empresas de base tecnológica. Não deixa de ser de base tecnológica a grande empresa que sistematicamente explora inovações intensivas em Pesquisa e Desenvolvimento $-\mathrm{P} \& \mathrm{D}$, tais como as dos setores farmacêutico e eletro-eletrônico. Quanto à segunda característica, os autores reconhecem a dificuldade de definir

\section{Um parque tecnológico não é necessariamente uma incubadora, a não ser que tenha mecanismos para dar sustentação às empresas nascentes. - • • •}

empresa independente e consideram que pode haver diversos tipos de vínculos ligando os empreendedores das novas empresas com os de outras já estabelecidas ${ }^{3}$. A independência não é essencial à caracterização das empresas de base tecnológica. Com as novas estratégias de risco (new ventures), muitas empresas desse tipo têm sua origem em grandes empresas que buscam firmar sua presença em novas áreas tecnológicas, através da criação de novas empresas de base tecnológica ou da associação com empresas desse tipo já existentes.

Para Rogers e Chen ${ }^{4}$, a indústria de alta tecnologia se caracteriza por empregar pessoas altamente qualificadas, muitas delas cientistas, e apresentar altas taxas de crescimento, uma elevada proporção de gastos em P\&D por venda e um mercado de natureza mundial para os seus produtos. O que caracteriza a tecnologia dessa indústria é o fato de se modificar rápida e continuamente. De acordo com esses autores, os principais ramos dessa indústria são: eletrônico aeroespacial, químico, farmacêutico, de instrumentação e biotecnológico. Concluindo, é possível encontrar empresas de base tecnológica de qualquer
1. DORFMAN, N. Route 128 : the development of a regional high technology economy. Research Policy, v. 12, n. 3, p. 300, 1983.

2 BOLLINGER, Lynm; HOPE, Katherine, UTTERBACK, James M. A. Review of literature and hypotheses on new technology - based firms. Research Policy. North-Holland, v. 12, n. 2, p. 2, Jan./1983.

3. Idem, ibidem.

4. ROGERS, Everett M., CHEN, Ying-Chung Annie. Technology transfer and the technopolis. In: GLINW, Mary-Ann Von, MOHRNAN, Suran Albert (orgs.). Managing complexity in high technology. USA: Oxford University Press, 1990. 
5. DORFMAN, N. Op. cit., p. 301

\section{Idem, ibidem, p. 307.}

7. URIBE, Guillermo. Los viveros de empresas en Francia. In: Seminário Latinoamericano de Gestión Tecnológica: Anais. Bogotá, 19 a 22 set./1993, p. 449-60. tamanho; vinculadas ou não a grupos econômicos; isolados em termos espaciais ou formando aglomerados ou pólos tecnológicos.

\section{PóLOS TECNOLÓGICOS}

Os pólos científico-tecnológicos, ou simplesmente pólos tecnológicos, que hoje fazem parte do receituário de políticas explícitas de vários países, têm suas origens nas experiências bem-sucedidas do "Sillicon Valley" na Califórnia e da "Route 128" em Massachusetts. Esses pólos têm em comum o fato de constituírem agrupamento

\section{- $\bullet \bullet$ \\ Nos pólos tecnológicos ocorre a proliferação de empresas de alta tecnologia ou de base tecnológica, criando, dessa forma, novos segmentos industriais.}

de empresas de base tecnológica cuja criação decorre da existência de recursos humanos e laboratoriais ligados às IEPs de alto padrão localizadas nas proximidades. O "Sillicon Valley" teve como elemento aglutinador a Universidade de Stanford e, a partir de 1950, o Stanford Industrial Park. A "Route 128", próxima a Boston, teve e tem como elemento aglutinador as IEPs da região, particularmente o MIT - Massachussets Institute of Technology e a Universidade de Harvard. De acordo com Dorfman, esse aglomerado surgiu virtualmente de modo espontâneo, ao contrário do "Sillicon Valley", que foi cuidadosamente nutrido pela Universidade de Stanford, sob a liderança de Frederick Terman, no início dos anos $50 . \mathrm{Na}$ "Route 128 ", nem Harvard, nem o MIT se envolveram, enquanto instituições, na criação de empresas, embora essas instituições constituíssem as mais importantes fontes de empreendedores $^{5}$. Dentre os fatores que contribuíram para a formação do aglomerado de empresas em torno da Rota 128, Dorfman cita, além da disponibilidade de recursos humanos altamente qualificados pelas IEPs locais e da infra-estrutura tecnológica, a existência de capital de risco em abundância na região de Boston ${ }^{6}$.

As experiências desses pólos forneceram os dois modelos básicos para outras iniciativas: o modelo espontâneo da Rota 128 e o modelo do Vale do Silício, que trouxe a idéia de "parque" como elemento indutor e facilitador da interação entre as pesquisas das IEPs e as necessidades do setor produtivo. As iniciativas decorrentes de um planejamento formal geralmente têm como elemento central a criação de parques tecnológicos, criados com o objetivo de promover a criação de empresas e de centros de pesquisas para uso compartilhado em locais próximos às IEPs existentes. É o caso, por exemplo, do Stanford Institute Park.

No Reino Unido, foram criados mais de uma dezena de pólos planejados, baseados em parques, denominados science parks, que se caracterizam por serem empreendimentos privados, geralmente criados e geridos por grandes corporações em conjunto com os governos locais. É o caso, por exemplo, do Science Park de Manchester, localizado junto à Universidade de Manchester e que tem, entre os sócios fundadores, diversas grandes empresas, como a Ciba-Geigy e a Ferranti. Outros exemplos de science parks: St. John's Innovation Park, criado pelo St. John's College de Cambridge e o Oxford Science Park, um parque criado a partir de uma joint venture, entre o Magdalen College e a empresa Prudential Assurance. Esses parques oferecem às empresas nascentes acomodação em seus prédios ou galpões, além de apoio gerencial.

Na França, existem dezenas de iniciativas do tipo planejado e apoiadas em parques, denominadas technopolis, como mostra Uribe ${ }^{7}$.

Para esse autor, o conceito de technopole relaciona-se com o de "viveiro" de empresas. De acordo com uma definição do governo francês, citada pelo autor, "technopole ou parque científico é um lugar especialmente urbanizado para receber empresas de alta tecnologia, em particular as empresas criadas a partir das pesquisas locais". Essas empresas podem ser alojadas e assistidas durante 
os seus primeiros anos de existência, numa incubadora ou viveiro de empresas $^{8}$. O Parque de Sophia Antipolis, criado em 1969 em Nice, sul da França, a partir da iniciativa e do projeto do professor Pierre Latiffe, da prestigiada École de Mines de Paris, constitui um marco no movimento francês de retomada do desenvolvimento baseado em novas tecnologias. Nesse parque, que hoje abriga aproximadamente 400 empresas de base tecnológica de portes diferentes, também se instalaram escritórios regionais de diversos órgãos governamentais de apoio à Ciência e Tecnologia como, por exemplo, o INPI - Institut National de la Propriété Industrielle e a ANVAR - Agence Nationale de Valorization de la Recherche.

Conforme Medeiros et al., o modelo francês assemelha-se ao do Japão, onde as cidades tecnológicas, ou technopolis, são planejadas para funcionar junto às cidades de médio porte e se beneficiam de facilidades habitacionais, transportes, agrupamentos de empresas e de centros de P\&D 9 . Santos mostra que, na implantação dessas technopolis, o Ministério do Comércio Internacional e Indústria - MITI, órgão governamental que concebeu e apoiou esses empreendimentos, estabeleceu os seguintes critérios para a seleção de local para a sua instalação: existência de um pólo industrial, de IEPs e de conjuntos habitacionais para abrigar os profissionais atraídos para o pólo; proximidade de centros urbanos com aproximadamente 200 mil habitantes e existência de meios de transporte que permitam viagens de ida e volta aos grandes centros urbanos japoneses no mesmo dia ${ }^{10}$. Ainda conforme Santos, os fatores que atraíram os investidores para esses empreendimentos foram: grandes extensões de terras a preços inferiores aos das grandes cidades; desejo de viver em locais melhores que os centros urbanos; alto retorno dos investimentos; ampliação de recursos por parte dos bancos oficiais e existência de subsídios e empréstimos a juros reduzidos oferecidos pelas prefeituras locais ${ }^{11}$. A propósito, a importância dos governos locais tem sido destacada em praticamente todos os estudos sobre pólos tecnológicos e de modernização.

O fenômeno dos pólos tecnológicos não
A importância dos

governos locais tem sido

destacada em praticamente

todos os estudos sobre

pólos tecnológicos e de

modernização.

se restringe aos países citados. Alemanha, Austrália, Canadá, Coréia do Sul, Espanha, Finlândia, Itália, Israel e praticamente todos os países industrializados possuem pólos com diferentes formatos e organizações. Em Taiwan, o parque de Hsinchu, um misto de Zona de Processamento de Exportação com parque tecnológico, próximo a Taipé, abriga cerca de 150 empresas - dos ramos de telecomunicações e computadores, principalmente -, entre elas a ACER Computer, uma multinacional que no início da década de 80 era apenas uma pequena empresa. A Universidad Nacional Autónoma de México, talvez a maior da América Latina, criou o Sistema Incubador de Empresas Científicas y Tecnológicas, com o objetivo de apoiar empresas e parques próximos aos seus diversos centros e institutos de pesquisa. $\mathrm{Na} \mathrm{Ve}-$ nezuela, existe em andamento a formação de três iniciativas apoiadas pelo Consejo Nacional de Investigaciones Científicas y Tecnológicas - Conicit. São elas: a Incubadora de Empresas de La Universidad de Los Andes, em Mérida; o Centro Tecnológico Industrial, em Barquisimetro, apoiado por uma organização local, a Fundación para el Desarrollo de la Ciencia y la Tecnología de la Región Centro Occidental e o Parque Tecnológico de Sartenejas, próximo a Caracas e vinculado à Universidade Simón Bolívar.

Nem toda região ou local que possua IEPs de alto nível terá condições de desenvolver pólos tecnológicos. A experiência internacional mostra que o sucesso desses pólos depende também da existência de um ambiente industrial dinâmico. Após examinar a experiência de oito science parks belgas e três holandeses, Dierdonck et al. concluíram que esses pólos eram muito mais conseqüências do desenvolvimento tecnológico regional do que propria-
8. Idem, ibidem, p. 452-3

9. MEDEIROS, José Adelino, MEDEIROS, Lucilia A., MARTINS, Theresa, PERILO, Sergio. Pólos, parques e incubadoras: a busca da modernizacão e competitividade. São Paulo: CNPq, Senai, Sebrae, 1992, p. 25.

10. SANTOS, Silvio A. Crią̧ão de empresas de alta tecnologia. São Paulo: Pioneira, BADESP, FEA/USP, 1987, p. 24-6.

11. Idem, ibidem, p. 26. 
12. DIERDONCK, Roland Van; DEBACKERE, Kaenraad, RAPPA, Michael A. An assessment of science parks: towards a better understanding of their role in the diffusion of technological knowledge. R\&DManagement, v. 21, n. 2, abril de 1991 p. 122.

13. DORFMAN, N. Op. cit., $p$ 302.

14. ETO, Hajime, FUJITA, Mamoru. Regularities in the growth of high technology industries in regions. Research Policy, v. 18, n. 3, junho de 1989 , p. 150.

15. DIERDONCK et al. Op. cit., p. 120.

16. MEDEIROS, J. A. et al. Op. cit., p. 23.

17. Idem, ibidem, p. 164. mente suas causas ${ }^{12}$. Vale lembrar Dorfman, quando aponta como uma das características da região de Massachusetts uma notável especialização nas áreas de eletrônica em períodos anteriores ao boom da "Route 128"13. Eto e Fujita, analisando o fenômeno das empresas de alta tecnologia do Japão, verificaram que estas tendem a surgir onde já existem outras atuando nos mesmos campos de atividade. Essa tendência, que os autores denominam de efeito de auto-reprodução, associa-se à existência de diversas vantagens acumuladas na região, como acumulação de conhecimentos tecnológicos, estilo gerencial, redes de comunicação intangíveis, educação da força de trabalho e outras que, genericamente, podem ser chamadas de "cultura" da região ${ }^{14}$. Essas vantagens regionais atuam como fatores redutores de

\section{A tendência dos pólos informais é de buscar cada vez mais uma coordenação que amplifique o potencial local.}

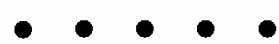

custo e de risco para as empresas do pólo. Cada uma pode se beneficiar do aprendizado desenvolvido pelas demais, pois parte dele extravasa para o ambiente. Além disso, podem ocorrer entre as empresas diversos tipos de cooperação, como a realização de projetos de $P \& D$ em conjunto. As IEPs da região constituem locus importantes para que essas vantagens possam ser melhor e rapidamente absorvidas pelas empresas. Porém, como advertem Dierdonck et al., elas representam apenas um nó da extensa rede constituída pela comunidade global de profissionais de interesse da indústria de alta tecnologia ${ }^{15}$. Tal constatação não diminui a importância dessas IEPs, ao contrário, elas podem atuar como elementos de ligação das empresas locais com essa comunidade de profissionais dispersa no mundo todo, quer em função das suas próprias atividades, quer pelo seu envolvimento com essas empresas.

\section{TIPOS DE PÓLOS TECNOLÓGICOS E A EXPERIEENCIA BRASILEIRA}

Com base na experiência brasileira, Medeiros et al. apresentam três configurações ou formatações básicas de pólos científico-tecnológicos. São eles: pólos com estrutura informal, com estrutura formal e parques tecnológicos. No primeiro caso, pólos com estrutura informal, as empresas e IEPs estão dispersas pela cidade sem qualquer estrutura formal que facilite a interação entre esses agentes, embora existam ações sistematizadas e projetos conjuntos que proporcionem alguma interação entre eles. Exemplos: pólo de Campinas e de São José dos Campos ${ }^{16}$. Esse tipo de formatação corresponde ao da Rota 128, antes mencionado. O pólo de São José dos Campos deveu-se à criação do Centro Técnico Aeroespacial - CTA e do Instituto Nacional de Pesquisas Espaciais - INPE. Em torno dessas IEPs surgiram diversas empresas, tais como: Embraer, Engesa, Amplimatic, ABC Sistemas Eletrônicos e outras, que no seu conjunto chegaram a criar mais de 10.000 empregos, segundo Medeiros et $\mathrm{ll}^{17}$.

O pólo de Campinas, que se desenvolveu inicialmente em torno da Unicamp e Pucamp, passou a contar depois com diversos laboratórios ou centros de P\&D como o CPqD da Telebrás, o Centro Tecnológico de Informática - CTI, a Cia. de Desenvolvimento Tecnológico - Codetec e o Laboratório Nacional de Luz Sincrotron - LNLS. O LNLS, uma unidade de pesquisa do $\mathrm{CNPq}-\mathrm{Con}-$ selho Nacional de Desenvolvimento Científico e Tecnológico - criada em 1987, conta com um acelerador linear de elétrons $e$ um acelerador circular está sendo construído no momento. Parte dos seus equipamentos foi projetado e construído internamente com envolvimento ativo de empresas e IEPs locais, o que demonstra o elevado nível de desenvolvimento tecnológico da região.

A tendência dos pólos informais é de buscar cada vez mais uma coordenação que amplifique o potencial local. Em São José dos Campos foi criada a Fundação Pólo Tecnológico de São José dos Campos e Vale do Paraíba - Polovale, em 1990, com o objetivo de criar e gerir pólos tecnológi- 
cos nessa região. Em Campinas foi criada em 1992 a Cia. de Desenvolvimento do Pólo de Alta Tecnologia de Campinas Ciatec, uma empresa de economia mista formada pela Unicamp e pela Prefeitura de Campinas. A Ciatec possui duas áreas urbanizadas e com serviços industriais priblicos prontas para receber empresas de base tecnológica, inclusive as de grande porte.

$\mathrm{Na}$ configuração pólo com estrutura formal, as empresas e IEPs, embora dispersas, são coordenadas, estimuladas e apoiadas por uma entidade formalmente constituída para isso ${ }^{18}$. São exemplos desse tipo de pólo a Ciatec e o Pólo de Alta Tecnologia de São Carlos, cuja entidade coordenadora é a Fundação Parque de Alta Tecnologia de São Carlos. De acordo com Torkomian e Lima, o pólo tecnológico de São Carlos, que conta com mais de $50 \mathrm{em}$ presas atuando nas áreas de novos materiais, equipamentos industriais, informática, ótica, mecânica de precisão e química fina, teve sua origem no Instituto de Física e Química e no Departamento de Engenharia Mecânica e Eletrônica da USP, bem como no Departamento de Engenharia de Materiais da UFSC ${ }^{19}$. Outras cidades que possuem pólos com estruturas formais: Campina Grande, Curitiba e Florianópolis.

$\mathrm{Na}$ configuração parque tecnológico as empresas estão reunidas num mesmo local, dentro do campus da IEP ou muito próximo a ele, e existe uma entidade coordenadora do parque, criada para facilitar a interação IEP -empresas e para gerenciar os recursos existentes e de uso compartilhado. Nesses parques, estão disponíveis para venda ou locação terrenos ou prédios, que abrigam uma incubadora ou condomínio de empresas ${ }^{20}$. Os pólos Bio-Rio e o Riotec se enquadram nesse modelo. $O$ primeiro está localizado no campus da UFRJ, na Ilha do Fundão, e conta com um galpão para abrigar cerca de 20 empresas nascentes e uma área urbanizada para receber empresas em caráter definitivo. Esse pólo é gerido pela Fundação Bio-Rio. O pólo Riotec, localizado em Jacarepaguá, é administrado pela Riotec S/A, empresa privada formada por cerca de 80 empresas acionistas.

As incubadoras podem fazer parte ou não de um pólo tecnológico. Um parque não é necessariamente uma incubadora, a não ser que tenha mecanismos para dar sustentação às empresas nascentes. São Carlos, Curitiba, Florianópolis e o Bio-Rio são pólos que também operam incubadoras. Para Medeiros et al., uma incubadora é um núcleo que abriga, usualmente, microempresas de base tecnológica dentro de um mesmo espaço físico, subdividido em módulos e localizados próximo às IEPs para se beneficiar dos seus recursos humanos e materiais ${ }^{21}$. De acordo com Uribe, as incubadoras têm por objetivo o desenvolvimento de empresas que já tenham uma existência legal, não se envolvendo na sua criação. Ou, dito de outra forma, não se tratam de maternidades de empresas, mas de assistência pós-natal. Seu objetivo final é o de proporcionar condições de autonomia às empresas nascentes ${ }^{22}$. A utilização de recursos com-

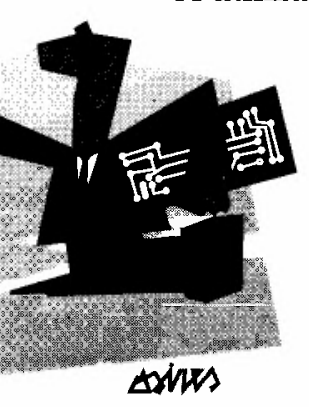
partilhados e o provimento de suporte gerencial contribuem para reduzir o elevado índice de mortalidade que ocorre entre as empresas nascentes isoladas.

A idéia de incubadora não concerne apenas às empresas baseadas em novas tecnologias. Existem incubadoras que não distinguem o tipo de tecnologia da empresa incubada. Por exemplo, o Núcleo de Iniciação Empresarial - Projeto Incubator, desenvolvido pela Federação e Centro das Indústrias do Estado de São Paulo-Fiesp/Ciesp, é um programa de assistência temporária às empresas nascentes, independentemente de serem baseadas em novas tecnologias ou em tecnologias tradicionais. Esse programa, que é coordenado pelo Departamento da Micro, Pequena e Média Indústria da Fiesp - Dempe, está operando no momento (abril de 1994) duas incubadoras. A incubadora do Brás, zona leste de São Paulo, ocupa uma antiga escola do Senai e pos-
18. Idem, ibidem, p. 25.

19. TORKOMIAN, A. L., LIMA, M. A. A. Administração de P\&D nas empresas do pólo de alta tecnologia de São Carlos. Re vista de Administração. São Paulo, v. 24, n. 1, p. 87, jan./mar. 1989.

20. MEDEIROS, J. A. et al. Op. cit., p. 26.

21. Idem, ibidem, p. 37.

22. URIBE, G. Op. cit., p. 53. 
23. SANTOS, S. A., RATTNER, H., BARALDO, Valter. Pólo de modernização empresarial: desenvolvimento nas micros pequenas empresas. Revista de Administração. São Paulo, v. 28 , n. 1, jan./mar. 1993

24. Idem, ibidem, p. 7.

25. MEDEIROS, J. A. et al. Op. cit., p. 31.
Um elemento fundamental da expansão da empresas de base tecnológica ou de alta tecnologia é a existência de fontes abundantes de capital de risco que, por sua vez, são incentivadas por instrumentos governamentais eficazes.

sui espaço para oito empresas. A de Itu, interior do estado, ocupa um prédio cedido pela Prefeitura e abriga dez empresas que atuam nas mais diversas áreas: confecções, conexões para fibra ótica, placas para circuitos impressos, sacos plásticos, brindes, mecânica fina etc. As empresas incubadas não pagam aluguel e rateiam despesas comuns como luz, água, telefone e salário dos funcionários da incubadora (recepcionista, faxineiro, segurança etc.). Além disso, recebem treinamentos e assistência gerencial durante o tempo que permanecerem incubadas, período este de doze meses, podendo ser ampliado segundo avaliação da coordenação do projeto.

\section{PÓLOS DE MODERNIZAÇÃO}

Esses pólos visam a transferir novos conhecimentos tecnológicos às empresas que atuam em setores tradicionais ou maduros, para dotá-las de competitividade. Enquanto nos pólos tecnológicos a proximidade com IEPs é uma condição necessária, nos pólos de modernização essa condição é desejável, mas nem sempre possível. De qualquer forma, a proximidade física não é uma condição essencial. Como os pólos científico-tecnológicos, os pólos de modernização também se caracterizam pelo uso compartilhado de recursos e se inscrevem como instrumentos para dinamizar a interface setor produtivo-entidades de Ciência e Tecnologia - C\&T.

De acordo com Santos et al., a filosofia básica do pólo de modernização é a de estimular os micros e pequenos empresários industriais e comerciais, de um mesmo setor ou ramo, para atuar de maneira conjunta na busca de competitividade ${ }^{23}$. A origem desses pólos, segundo esses autores, encontra-se na experiência italiana de Emília Romana, tendo como centro Bolog- na. $O$ esforço cooperativo de pequenas e médias empresas do setor de confecção fez com que essa região, antes uma das mais pobres do país, se tornasse próspera e exportadora de bens para toda a Comunidade Econômica Européia. Essas empresas contpartilham recursos como CAD/ CAM - Design Aided Computer/ Manufactering Aided Computer, máquinas de controle numérico, centros de pesquisas, serviços de informação etc. Além disso, a realização de compras e vendas em conjunto e o uso de marca coletiva ampliaram a competitividade dessas empresas, tanto no mercado interno quanto externo ${ }^{24}$.

Como advertem Medeiros et al., não é possível a transposição in totum dos mecanismos dos pólos tecnológicos para os de modernização. Como as novas tecnologias (informática, novos materiais etc.) estão na base de todos os setores, inclusive os tradicionais, isso gera impulsos no sentido de generalizar para estes os mesmos conceitos aplicáveis aos pólos científico-tecnológicos. De acordo com os autores, deve-se considerar que nos setores tradicionais existem formas diferenciadas de absorção de novas tecnologias, inclusive as de natureza administrativa ${ }^{25}$. A experiência brasileira conta atualmente com diversos pólos de modernização como o pólo de Itú, na área de cerâmica vermelha, e o pólo de Americana, na área têxtil.

O pólo de Americana e cidades vizinhas tem por objetivo a modernização do setor têxtil, a principal atividade dessa região. Ele nasceu do projeto "Pólo de Modernização para a Eficiência Coletiva", desenvolvido dentro de um convênio entre as seguintes entidades: Sindicato da Indústria de Tecelagem de Americana, Nova Odessa, Sumaré e Santa Bárbara d'Oeste (Sinditec); Secretaria de Ciência, Tecnologia e Desenvolvimento Econômico do Estado de São Paulo e Sebrae. Diversos grupos de trabalho foram formados e os problemas do setor foram identificados e classificados em quatro grandes famílias: problemas de comercialização, como guerra de preços, dificuldades para exportar, mercados reduzidos e a ameaça representada pela importação; problemas de produção como, por exemplo, novos equipa- 
mentos, falta de qualidade, manutenção deficiente, dificuldades com o tingimento e o acabamento; problemas com a matéria-prima, advindos, principalmente, do baixo poder de barganha das empresas locais frente aos fornecedores que impõem condições de vendas, de prazos, de qualidade e de preços desfavoráveis às empresas compradoras e problemas de gerenciamento como gestão de $\mathrm{RH}$, de custos, do fluxo financeiro, de materiais, da produção etc. Também fazem parte desse pólo os facionistas da região vinculados ao Sinditec ${ }^{26}$. De acordo com Medeiros et al., esse pólo foi inspirado no modelo italiano de associativismo ${ }^{27}$, assunto este já mencionado. As ações de modernização realizadas e em curso envolvem a aquisição de recursos para uso compartilhado como computadores, novas máquinas, contratação de estilistas e modelistas, bem como a realização de programas coletivos de treinamento, de suprimento e de distribuição. $\mathrm{O}$ aporte de conhecimentos técnicos tem sido feito pelas seguintes IEPs: USP, IPT e Senai.

\section{CAPITAL DE RISCO}

Nos países desenvolvidos de economia de mercado, a criação de novas empresas de base tecnológica, uma das principais formas de introduzir inovações em setores de ponta, tem sido facilitada pela existência de inúmeras fontes privadas de capital de risco (venture capital), como mostram, entre outros, Dorfman, Salomon, Florida e Kenney ${ }^{28}$. Sem a participação das organizações de capital de risco, provavelmente não se verificaria nesses países o crescimento explosivo do número de pequenas e médias empresas que operam nos setores das novas tecnologias. De acordo com Salomon, por capital de risco se designa o capital à procura de oportunidades de investimentos de alto risco, associados a ganhos potenciais elevados. Em relação às inovações, apresenta-se sob a forma de participação na criação de pequenas empresas especializadas em novas idéias ou tecnologias. O capital de risco não se limita a fornecer recursos financeiros para a nova empresa, ele consiste tam- bém no aporte de competências necessárias ao seu estabelecimento, à concepção da sua estratégia comercial e à sua organização e administração ${ }^{29}$.

Para Florida e Kenney, os capitalistas de risco investem no novo, em empreendimentos ainda não testados e que as instituições financeiras tradicionais ignoram. Eles são investidores ativos que se envolvem integralmente na criação de novas empresas. Esses dois autores entendem

\section{A participação governamental} nas atividades de risco associadas as inovações foi e continua sendo importante em todos os países onde elas existem.

que o crescimento do venture capital transformou o processo de inovações, dando origem a um novo modelo de inovação que integra os componentes do modelo baseado na iniciativa de pessoas empreendedoras e os do modelo baseado nas grandes corporações com funções de P\&D internalizadas. Nesse novo modelo, que transcende a dicotomia empreendedor versus corporação da teoria neo-schumpeteriana, as grandes e pequenas firmas se interagem de forma dinâmica e complementar no processo de inovação ${ }^{30}$. E de fato, de um total de 509 firmas de venture capital identificadas pelos autores, nos Estados Unidos, 44 delas eram subsidiárias de grandes corporações como a Xerox, a General Electric e a Lubrizol. A maioria dessas subsidiárias investem estrategicamente para diversificar as linhas de produtos, garantir sua presença em novas áreas tecnológicas ou iniciar o processo de aquisição ou desenvolvimento de uma sociedade com uma pequena empresa de sucesso $^{31}$. Outras fontes privadas de capital de risco são bancos, seguradoras, fundos de pensão, fundações privadas, bem como investidores individuais.

A participação governamental nas atividades de risco associadas às inovações foi e continua sendo importante em todos os países onde elas existem. Nos Estados
26. SINDICATO das Indústrias de Tecelagem de Americana, Nova Odessa, Sumaré e Santa Bárbara (Sinditec). Informativo Sinditec, n. 1, Americana, 1992.

27. MEDEIROS, J. A. et al. Op. cit., p. 174.

28. DORFMAN, N. Op. cit.; SA LOMON, J. J. Les politiques d'innovation en Europe. Futuri bles, Paris, maio/1989; FLORIDA, R. L., KENNEY, M. Venture capital financied innovation and technology chance in the USA. Research Policy, v. 17, n. 3, p. 119-37, 1988

29. SALOMON, J. J. Op. cit., p. 46

30. FLORIDA, R. L., KENNEY, $M$. 0p. cit., p. 126-9.

31. Idem, ibidem, p. 122. 
32. WAN, Victor. Financing high technology: the Australian venture capital market. Technovation. UK, v. 9, p. 337-55, 1989.
Unidos, esse tipo de atividade, que é fundamentalmente de caráter privado, ganhou impulso com a aprovação pelo Congresso, em 1958, do Small Business Investment Companies - SBIC Act, e conta atualmente com inúmeros incentivos na esfera federal, estadual e local. Em outros países, os governos tiveram uma atuação mais acentuada em decorrência de uma presença menor da iniciativa privada. Esse é o caso, por exemplo, do Reino Unido, da Alemanha e da Austrália. De acordo com

$\bullet \bullet \bullet \bullet$
O Brasil já apresenta
diversos pólos e parques
tecnológicos. A criação desses
pólos e sua sustentação diferem
em muito da experiência
internacional, principalmente
pela ausência de capital
de risco no país.
$\bullet \bullet \bullet \bullet \bullet$

Wan, o governo australiano criou em 1984 o Management and Investment Companies Program para compensar a falta de capital de risco privado aplicado ao desenvolvimento de novos negócios. Para isso, o governo, entre outras medidas, alterou a legislação tributária com o objetivo de estimular o surgimento de investidores privados, dando a estes o direito de abater dos seus impostos devidos até $100 \%$ dos investimentos feitos em negócios apoiados pelo programa e que, em geral, devem ser negócios pequenos, inovadores, de rápido crescimento, orientados para exportações e geradores de empregos ${ }^{32}$. A existência desse tipo de atividade de risco e a sua interação com diversos instrumentos de política governamental constituem um importante estímulo à criação de novas empresas baseadas em inovações tecnológicas pioneiras.

O Brasil já apresenta diversos pólos e parques, alguns deles citados aqui. A criação desses pólos e sua sustentação diferem em muito da experiência internacional, principalmente pela ausência de ca- pital de risco no país. Só em 1986 é que as empresas de capital de risco receberam um tratamento tributário diferenciado das holdings tradicionais (Decreto-Lei no 2.287/ 86). Mesmo assim, não é nada comparado com o que existe nos países ricos. As empresas privadas de capital de risco, denominadas "companhias de participação", têm atuado muito mais como empresas financeiras tradicionais, dando preferência às grandes empresas e canalizando recursos para empreendimentos mais seguros, em geral não relacionados com a incorporação de novas tecnologias.

$\mathrm{Na}$ área pública, a Financiadora de Estudos e Projetos - Finep, que é a maior agência de fomento para a C\&T no Brasil, também prevê a aplicação de capital de risco entre suas modalidades de apoio financeiro às empresas nacionais. Tanto no Programa de Apoio ao Desenvolvimento Tecnológico da Empresa Nacional - ADTEN, quanto no Programa de Apoio à Consultoria Nacional - ACN, a Finep mantém operações de risco, mediante participação acionária, participação nos resultados do projeto ou participação nos resultados da empresa. Porém essas modalidades de risco têm sido pouco utilizadas, pois a grande maioria das operações contratadas continua sendo de financiamentos reembolsáveis. O BNDESPAR opera modalidades de risco para capitalização de pequenas empresas de base tecnológica em fase de start-up ou de expansão (Contec - Condomínio de Capitalização de Empresas de Base Tecnológica), cujo apoio pode ser realizado de modo indireto, através da participação acionária em holdings regionais. Também nesse caso a aplicação de capital de risco ainda é incipiente.

\section{CONSIDERAÇOEES FINAIS}

A condição básica para a criação de pólos tecnológicos é a existência de IEPs de nível elevado, pois o insumo fundamental desses empreendimentos é o conhecimento científico e tecnológico. Trata-se, portanto, de um fator localizacional bási$\mathrm{co}$, mas que não dispensa os tradicionais como a proximidade com vias de acesso, 
com os consumidores etc. O fortalecimento das IEPs locais, bem como das demais entidades de Ciência e Tecnologia da região são fundamentais para o surgimento e a sustentação de empresas de base tecnológica. Além disso, é fundamental o desenvolvimento de comportamentos empreendedores nessas IEPs, pois esses pólos baseiam-se em grande parte na iniciativa de pessoas, geralmente seus pesquisadores e professores, bem como os diversos profissionais formados por elas.

O Brasil já apresenta diversas experiências consolidadas e em formação, embora o número de pólos e das empresas que gravitam ao seu redor ainda seja muito modesto, quando comparado ao dos países desenvolvidos. O pólo de São Carlos, por exemplo, apresenta cerca de 50 empresas de base tecnológica, quase todas de pequeno porte, enquanto que em torno da Rota 128 há mais de mil empresas desse tipo, sendo algumas gigantes, como a Digital Equipments. Como foi mostrado, um elemento fundamental da expansão das empresas de base tecnológica ou de alta tecnologia é a existência de fontes abundantes de capital de risco, que, por sua vez, são incentivadas por instrumentos governamentais eficazes. No Brasil, a aplicação de capital de risco, público ou privado, em idéias, inovações ou empresas de base tecnológica nascentes ainda é uma atividade incipiente e que conta com poucos estímulos reais. Numa economia tumultuada como a nossa, dificilmente as atividades de risco, em geral, ou aquelas associadas às inovações tecnológicas pioneiras, em particular, são encaradas como alternativas de negócios rentáveis e atrativos por parte do empresariado e de outros tipos de investidores.

A quantidade de regiões ou locais com pólos tecnológicos está limitada à existência de IEPs de alto nível em suas proximidades. Na obra de Medeiroset al., uma das mais completas sobre o tema, são apresentadas doze cidades com pólos tecnológicos no Brasil, algumas contendo incubadoras. São elas: Brasília, Campina Grande, Campinas, Curitiba, Florianópolis,
A condição básica para a criação de pólos tecnológicos é a existência de IEPs de nível elevado, pois o insumo fundamental desses empreendimentos é o conhecimento científico e tecnológico.

Fortaleza, Porto Alegre, Recife, Rio de Janeiro, Santa Rita do Sapucaí, São Carlos e São José dos Campos. Em todas essas cidades existem IEPs de excelência e com longa tradição em pesquisa nas áreas de fronteiras do conhecimento. A existência desse fator no local é condição necessária para o surgimento e o sucesso dos pólos tecnológicos. A esse fator, devem-se agregar outros, ligados ao envolvimento do empresariado, de investidores e dos governos.

Os pólos de modernização não estão submetidos à mesma condição limitante. A presença no local de IEPs de alto nível não é condição sine qua non para a sua implementação, pois o aporte de conhecimentos pode ser feito à distância, através de atividades de extensão. Considerando que as atividades de uma IEP podem ser genericamente agrupadas em atividades de ensino, de extensão e de pesquisa, os pólos tecnológicos relacionam-se mais estreitamente com estas últimas, enquanto os de modernização, com as de extensão extra-muros. Mas não um extensionismo tradicional praticado de modo isolado, e sim aquele potencializado pelo associativismo dos beneficiados. Em tese, qualquer agrupamento de estabelecimentos que opere em qualquer ramo da atividade econômica, inclusive nas áreas agrícolas, pode ser objeto de uma intervenção planejada com o objetivo de promover a sua atualização tecnológica e organizacional, transformando este agrupamento no núcleo inicial de um pólo de modernização. 